677T allele frequencies have been reported in Canadian Inuit $(6.1 \%),{ }^{14}$ Manitoba neonates $(24.97 \%),{ }^{15}$ French Canadians $(38 \%)^{16}$ and our neonatal $(27.3 \%)^{8}$ and adult (40\%) control and study groups. ${ }^{9}$ Considering the regional variations in MTHFR allele distributions, it is not completely surprising that some studies have recognised the common MTHFR mutations only in trans positions. ${ }^{1-4}$ It is quite possible that in certain populations, such as on the island of Crete recombinant events between MTHFR $677 \mathrm{~T}$ and $1298 \mathrm{C}$ mutations are very rare occurrences and identification of any cis mutations would require genotyping of a large number of individuals.

Although Zetterberg et al. ${ }^{1}$ investigated early spontaneous abortions, with all foetal deaths occurring before 6 and 20 weeks of gestation, the inherent limitation of their study, as well as other studies investigating foetal viability, ${ }^{8}$ is that very early spontaneous abortions are not examined in study populations. The true contribution of MTHFR mutations to reduced foetal viability may be difficult to determine, as the majority of pregnancies that spontaneously terminate before 6 weeks of gestation is not identified clinically. It is evident that additional large-scale population studies are required to fully elucidate the role of MTHFR mutations in contributing to decreased foetal viability. It also appears that regionally based studies are necessary to assess risks for specific populations.

Phillip A Isotalo

Department of Pathology and Laboratory Medicine, Mayo Clinic, Rochester, Minnesota, USA James G Donnelly Department of Pathology, New York University School of Medicine, New York, New York, USA

\section{References}

1 Zetterberg H, Regland B, Palmer $M$ et al: Increased frequency of combined methylenetetrahydrofolate reductase C677T and A1298C mutated alleles in spontaneously aborted embryos. Eur J Hum Genet 2002; 10: 113-118.

2 van der Put NMJ, Gabreels F, Stevens EMB et al: A second common mutation in the methylenetetrahydrofolate reductase gene: an additional risk factor for neural-tube defects?. Am J Hum Genet 1998; 62: 1044-1051.
3 Rady PL, Tyring SK, Hudnall SD et al: Methylenetetrahydrofolate reductase (MTHFR): the incidence of mutations C677T and A1298C in the Ashkenazi Jewish population. Am J Med Genet 1999; 86: 380-384.

4 Stegmann K, Ziegler A, Ngo ET et al: Linkage disequilibrium of MTHFR genotypes 677C/T-1298A/C in the German population and association studies with neural tube defects (NTD). Am J Med Genet 1999; 87: 23-29.

5 Weisberg I, Tran P, Christensen B, Sibani S, Rozen R: A second genetic polymorphism in methylenetetrahydrofolate reductase (MTHFR) associated with decreased enzyme activity. Mol Genet Metab 1998; 64: 169-172.

6 Friedman G, Goldschmidt N, Friedlander Y et al: A common mutation $\mathrm{A} 1298 \mathrm{C}$ in human methylenetetrahydrofolate reductase gene: association with plasma total homocysteine and folate concentrations. J Nutr 1999; 129: 1656-1661.

7 Skibola CF, Smith MT, Kane E et al: Polymorphisms in the methylenetetrahydrofolate reductase gene are associated with susceptibility to acute leukemia in adults. Proc Natl Acad Sci USA 1999; 96: 12810-12815.

8 Isotalo PA, Wells GA, Donnelly JG: Neonatal and fetal methylenetetrahydrofolate reductase genetic polymorphisms: an examination of C677T and A1298C mutations. Am J Hum Genet 2000; 67: 986-990.

9 Isotalo PA, Donnelly JG: Prevalence of methylenetetrahydrofolate reductase mutations in patients with venous thrombosis. Mol Diagn 2000; 5: 59-66.

10 Hanson NQ, Aras O, Yang F, Tsai MY: C677T and A1298C polymorphisms of the methylenetetrahydrofolate reductase gene: incidence and effect of combined genotypes on plasma fasting and post-methionine load homocysteine in vascular disease. Clin Chem 2001; 47: 661-667.

11 Volcik KA, Blanton SH, Northrup H: Examinations of methylenetetrahydrofolate reductase C677T and A1298C mutations - and in utero viability [Letter]. Am J Hum Genet 2001; 69: 1150-1152.

12 Donnelly JG: The silent T1317C mutation of methylenetetrahydrofolate reductase should not interfere with MboII restriction isotyping of the reported A1298C mutation. Mol Genet Metab 1999; 68: 511.

13 Donnelly JG, Isotalo PA: Reply to 'Examinations of methylenetetrahydrofolate reductase C677T and A1298C mutations - and in utero viability' [Letter]. Am J Hum Genet 2001; 69: 1152-1153.

14 Hegele RA, Tully C, Young TK, Connelly PW: V677 mutation of methylenetetrahydrofolate reductase and cardiovascular disease in Canadian Inuit [Letter]. Lancet 1997; 349: 1221-1222.

15 Mogk RL, Rothenmund H, Evans JA, Carson N, Dawson AJ: The frequency of the C677T substitution in the methylenetetrahydrofolate reductase gene in Manitoba [Letter]. Clin Genet 2000; 58: $406-408$.

16 Frosst P, Blom HJ, Milos R et al: A candidate genetic risk factor for vascular disease: a common mutation in methylenetetrahydrofolate reductase [Letter]. Nature Genet 1995; 10: 111-113.

\title{
Reply to 'MTHFR C677T and A1298C polymorphisms and mutated sequences occurring in cis'
}

European Journal of Human Genetics (2002) 10, 579-582. doi:10.1038/sj.ejhg.5200863

Isotalo and Donnelly comment in their letter (2002, in this issue) on the conflicting reports regarding the prevalence of MTHFR 677T and 1298C alleles occurring in cis.
In our study we did not find any triple or quadruple MTHFR mutation combinations either in the spontaneous abortion group $(n=80)$ or in the control group which 
consisted of randomly chosen healthy blood donors $(n=125)$, suggesting complete linkage disequilibrium between the two polymorphisms in these two groups of Cretan descent. ${ }^{1}$ Moreover, we have until now analysed $>500$ individuals of Swedish descent and only detected $677 \mathrm{~T}$ and $1298 \mathrm{C}$ alleles in trans configuration (unpublished data). Most studies in the field have reported no or few cases with $677 \mathrm{~T}$ and $1298 \mathrm{C}$ alleles in the cis configuration. $^{2-9}$ We have recently analysed an Italian population consisting of 335 individuals (155 patients with arterial or venous thrombosis and 180 controls) using the minisequencing technique employed in our spontaneous abortion study. ${ }^{1}$ We found two individuals from Southern and one from Northern Italy with 677TT/1298AC genotypes (Figure 1). The genotypes were verified by dideoxy sequencing using the ABI PRISM Big Dye ${ }^{\mathrm{TM}}$ Terminator Cycle Sequencing kit (PE Applied Biosystems). No 677CT/1298CC or 677TT/1298CC genotypes were detected. These data, together with the studies mentioned above, demonstrate that 677T and 1298C alleles in cis are possible, but indeed very rare, and support the hypothesis that triple mutation combinations probably reflect recombinant events having occurred either de novo or in the relatively late ancestral history of specific sub-populations. Obviously, it is not excluded that specific subpopulations, such as the ones studied by Isotalo et al. ${ }^{10,11}$ may display higher frequencies of triple (and possibly quadruple) mutation combinations. In these sub-populations it is also possible that triple and quadruple mutation combinations may have a negative influence on embryonic survival. This would be in agreement with our results which demonstrated a negative influence of MTHFR mutated alleles on foetal viability in the absence of folic acid supplementation; ${ }^{1}$ the more $677 \mathrm{~T}$ and $1298 \mathrm{C}$ alleles in one individual, the worse clinical effects during times of folate deficiency, such as pregnancy.

In their letter (2002, in this issue), Isotalo and Donnelly clarify the ethnicity of their Canadian study and control populations in which a very high frequency of $677 \mathrm{TT} / 1298 \mathrm{AC}$ genotypes was detected (9.2 and $12.5 \%$ for cases and controls, respectively). ${ }^{11}$ The populations consisted of Canadians with a predominantly European (Celtic) descent. Following this clarification, it seems possible that the conflicting results between the studies by Weisberg et al. ${ }^{3}$ and Isotalo et al. ${ }^{11}$ with regard to the prevalence of triple mutation combinations might be explained by differences in ethnicity. However, Volcik et al. ${ }^{12}$ also studied a Canadian population of European descent, composed of patients with spina bifida and their parents. Still, Volcik et al. ${ }^{12}$ reported lower frequencies of $677 \mathrm{~T}$ and $1298 \mathrm{C}$ alleles (32 and 35\%, respectively, compatible with most European populations) than Isotalo et al. ${ }^{11}$ (40 and 48\%, respectively, of healthy controls). If anything, one would expect a higher frequency of $677 \mathrm{~T}$ and $1298 \mathrm{C}$ alleles in a group consisting of spina bifida patients and their relatives. The Celtic influence in the study by Isotalo and Donnelly ${ }^{11}$ does not likely explain
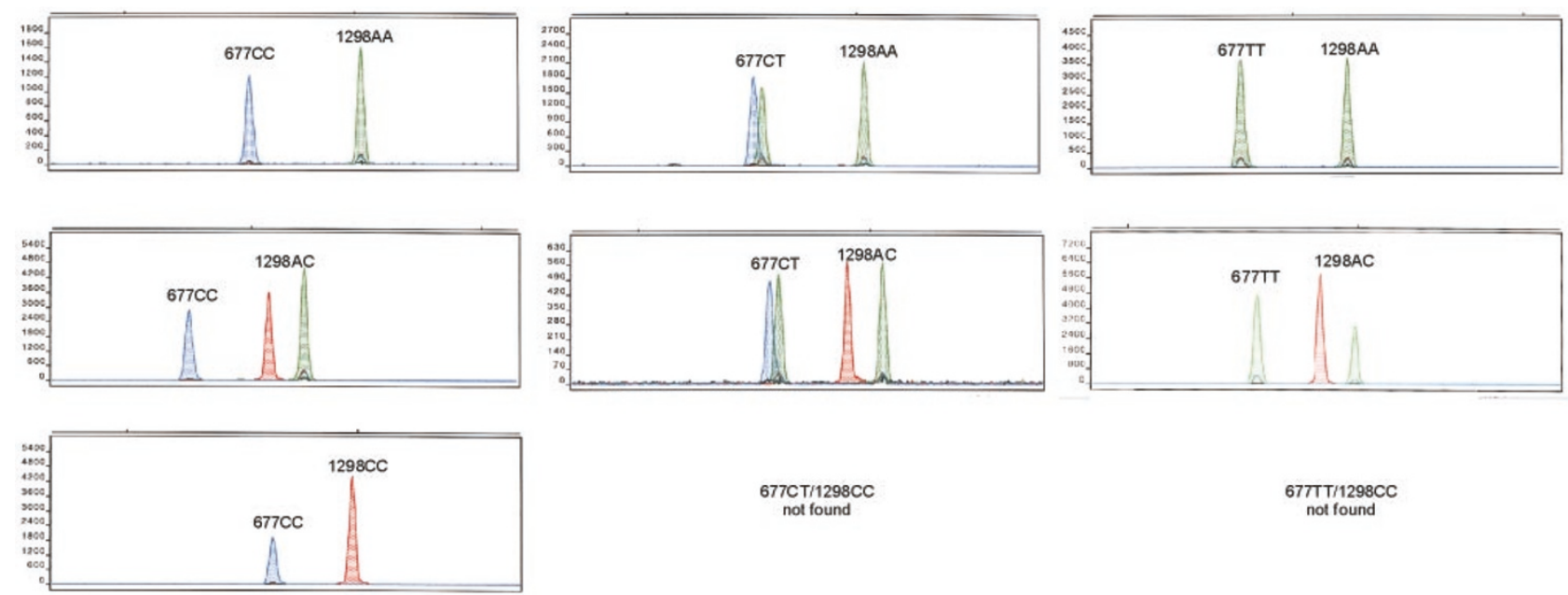

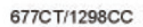
not found

Figure 1 Multiplex minisequencing electropherograms for seven different MTHFR C677T and A1298C genotypes. The technique has been previously described in detail. ${ }^{1}$ A blue peak represents a $C$ nucleotide (wild type) at position 677 in the MTHFR gene. A green peak to the left in the electropherogram represents a T nucleotide at the same position. A green peak to the right in the electropherogram represents an A nucleotide (wild type) at position 1298 in the MTHFR gene. A red peak represents a $C$ nucleotide at the same position. Three individuals with 677TT/1298AC genotypes were identified in an Italian population consisting of 335 individuals. No 677CT/ $1298 C$ C or $677 T T / 1298 C C$ genotypes were found. 
the difference, since the 677T allele frequency in Celtic populations is lower (approximately 33\%). ${ }^{13}$ It should be remembered that patterns generated with the MTHFR C677T and A1298C restriction fragment length polymorphism (RFLP) techniques may be difficult to interpret. It is not excluded that the very diverse MTHFR C677T and A1298C allele frequencies reported in the literature, even in closely related or essentially identical populations with regard to ethnicity, to some extent could be explained by misidentification of genotype. Furthermore, one inherent problem with RFLP is its sensitivity to silent polymorphisms, which may affect restriction enzyme recognition sites and give false genotype results.

It is unfortunate that the reports of triple and quadruple MTHFR mutation combinations, especially the ones by Isotalo et al. ${ }^{10,11}$ were not confirmed by independent techniques, such as DNA sequencing. We suggest that DNA sequencing should be included in the MTHFR genotyping algorithm when RFLP patterns compatible with 677TT/1298AC, 677CT/1298CC or 677TT/1298CC genotypes are detected. Future studies using this approach will most likely be helpful in revealing the true prevalence of mutated MTHFR alleles in cis configuration in different populations. Lastly, and this we are inclined to think is the most important element of our study, ${ }^{1}$ the strong association between combined MTHFR C677T and A1298C mutated alleles and compromised foetal survival suggests that periconceptional folic acid supplementation may lower the incidence of spontaneous abortion and possibly increase the frequency of mutated alleles in adults. Compatible with this hypothesis, mandatory use of folic acid during pregnancy has been reported to increase the prevalence of 677T homozygosity in a Spanish population. ${ }^{14}$

Henrik Zetterberg*, Lars Rymo Department of Clinical Chemistry and Transfusion Medicine, Sahlgrenska University Hospital, Göteborg University, Sweden

Antonio Coppola

Department of Clinical and Experimental Medicine, University of Naples 'Federico II', Naples, Italy

Armando D'Angelo Coagulation Service and Thrombosis Research Unit, I.R.C.C.S.H.S. Raffaele, Milan, Italy

Demetrios A Spandidos Department of Virology, Medical School, University of Crete, Heraklion, Crete, Greece

\author{
Kaj Blennow \\ Institute of Clinical Neuroscience, \\ Department of Experimental Neuroscience, \\ Sahlgrenska University Hospital, Göteborg University, Sweden \\ *Correspondence: Henrik Zetterberg, \\ Department of Clinical Chemistry and Transfusion Medicine, \\ Sahlgrenska University Hospital, Göteborg University, \\ 5-71375 Gothenburg, Sweden \\ E-mail: henrik.zetterberg@clinchem.gu.se
}

\section{References}

1 Zetterberg H, Regland B, Palmér M et al: Increased frequency of combined methylenetetrahydrofolate reductase C677T and A1298C mutated alleles in spontaneously aborted embryos. Eur J Hum Genet 2002; 10: 113-118.

2 van der Put NMJ, Gabreëls F, Stevens EMB et al: A second common mutation in the methylenetetrahydrofolate reductase gene: an additional risk factor for neural-tube defects?. Am J Hum Genet 1998; 62: 1044-1051.

3 Weisberg I, Tran P, Christensen B, Sibani S, Rozen R: A second genetic polymorphism in methylenetetrahydrofolate reductase (MTHFR) associated with decreased enzyme activity. Mol Genet Metab 1998; 64: 169-172.

4 Chango A, Boisson F, Barbé $\mathrm{F}$ et al: The effect of $677 \mathrm{C} \rightarrow \mathrm{T}$ and $1298 \mathrm{~A} \rightarrow \mathrm{C}$ mutations on plasma homocysteine and 5,10-methylenetetrahydrofolate reductase activity in healthy subjects. Br J Nutr 2000; 83: 593-596.

5 Stegmann K, Ziegler A, Ngo ETKM et al: Linkage disequilibrium of MTHFR genotypes 677C/T-1298A/C in the German population and association studies in probands with neural tube defects (NTD). Am J Med Genet 1999; 87: 23 - 29.

6 Friedman G, Goldschmidt N, Friedlander Y et al: A common mutation A1298C in human methylenetetrahydrofolate reductase gene: association with plasma total homocysteine and folate concentrations. J Nutr 1999; 129: 1656-1661.

7 Hanson NQ, Aras O, Yang F, Tsai MY: C677T and A1298C polymorphisms of the methylenetetrahydrofolate reductase gene: incidence and effect of combined genotypes on plasma fasting and post-methionine load homocysteine in vascular disease. Clin Chem 2001; 47: 661-666.

8 Rady PL, Tyring SK, Hudnall SD et al: Methylenetetrahydrofolate reductase (MTHFR): the incidence of mutations C677T and A1298C in the Ashkenazi Jewish population. Am J Med Genet 1998; 86: 380-384.

9 Rosenberg N, Murata M, Ikeda Y, Opare-Sem O, Zivelin A, Geffen E, Seligsohn U: The frequent 5,10-methylenetetrahydrofolate reductase C677T polymorphism is associated with a common haplotype in whites, Japanese, and Africans. Am J Hum Genet 2002; 70: $758-762$.

10 Isotalo PA, Wells GA, Donnelly JG: Neonatal and fetal methylenetetrahydrofolate reductase genetic polymorphisms: an examination of C677T and A1298C mutations. Am J Hum Genet 2000; 67: 986-990.

11 Isotalo PA, Donnelly JG: Prevalence of methylenetetrahydrofolate reductase mutations in patients with venous thrombosis. Mol Diagn 2000; 5: 59-66.

12 Volcik KA, Blanton SH, Northrup H: Examinations of methylenetetrahydrofolate reductase C677T and A1298C mutations - and in utero viability. Am J Hum Genet 2001; 69: 1150-1152. 
13 Botto LD, Yang Q: 5,10-Methylenetetrahydrofolate reductase gene variants and congenital anomalies: a HuGE review. $A m J$ Epidemiol 2000; 151: 862-877.
14 Munoz-Moran E, Dieguez-Lucena JL, Fernandez-Arcas N, PeranMesa S, Reyes-Engel A: Genetic selection and folic acid intake during pregnancy. Lancet 1998; 352: 1120-1121. 